\title{
Effectiveness of different memory training programs on improving hyperphagic behaviors of residents with dementia: a longitudinal single-blind study
}

This article was published in the following Dove Press journal:

Clinical Interventions in Aging

23 May 2016

Number of times this article has been viewed

\author{
Chieh-Chun Kao ${ }^{1,2}$ \\ Li-Chan $\operatorname{Lin}^{3}$ \\ Shiao-Chi Wu ${ }^{4}$ \\ Ker-Neng $\operatorname{Lin}^{5,6}$ \\ Ching-Kuan $\mathrm{Liu}^{7,8}$
}

'Department of Nursing, National Yang-Ming University, Taipei, ${ }^{2}$ Department of Nursing, Ching Kuo Institute of Management and Health, Keelung, ${ }^{3}$ Institute of Clinical Nursing, ${ }^{4}$ Institute of Health and Welfare Policy, National Yang-Ming University, ${ }^{5}$ Neurological Institute, Taipei Veterans General Hospital, Taipei, ${ }^{6}$ Department of Psychology, Soochow University, Taipei, Taiwan; ${ }^{7}$ Department of Neurology, Kaohsiung Medical University Hospital, ${ }^{8}$ Department of Neurology, Faculty of Medicine, College of Medicine, Kaohsiung Medical University, Kaohsiung, Taiwan

Correspondence: Li-Chan Lin Institute of Clinical Nursing, National Yang-Ming University, I55, Li-Nong Street, Sec 2, Taipei, Taiwan, Republic of China

Tel/fax +88622826 7I59

Email lichan2009@gmail.com
Background: Hyperphagia increases eating-associated risks for people with dementia and distress for caregivers. The purpose of this study was to compare the long-term effectiveness of spaced retrieval (SR) training and SR training combined with Montessori activities $(\mathrm{SR}+\mathrm{M})$ for improving hyperphagic behaviors of special care unit residents with dementia.

Methods: The study enrolled patients with dementia suffering from hyperphagia resident in eight institutions and used a cluster-randomized single-blind design, with 46 participants in the SR group, 49 in the SR + M group, and 45 participants in the control group. For these three groups, trained research assistants collected baseline data on hyperphagic behavior, pica, changes in eating habits, short meal frequency, and distress to caregivers. The SR and SR + M groups underwent memory training over a 6 -week training period ( 30 sessions), and a generalized estimating equation was used to compare data of all the three groups of subjects obtained immediately after the training period and at follow-ups 1 month, 3 months, and 6 months later.

Results: Results showed that the hyperphagic and pica behaviors of both the SR and SR + M groups were significantly improved $(P<0.001)$ and that the effect lasted for 3 months after training. The improvement of fast eating was significantly superior in the SR + M group than in the SR group. The improvement in distress to caregivers in both intervention groups lasted only until the posttest. Improvement in changes in eating habits of the two groups was not significantly different from that of the control group.

Conclusion: SR and SR + M training programs can improve hyperphagic behavior of patients with dementia. The SR + M training program is particularly beneficial for the improvement of rapid eating. Caregivers can choose a suitable memory training program according to the eating problems of their residents.

Keywords: dementia, hyperphagia, spaced retrieval training, Montessori-based activities, longitudinal research

\section{Introduction}

The prevalence of hyperphagia in patients with dementia is $\sim 23 \%-51 \%$ and tends to occur in patients in the middle stage of dementia. ${ }^{1,2}$ The main features of hyperphagia include increased appetite (eg, frequent food searches or requests for food), faster eating speed, and increased amount of food consumed. ${ }^{1,3,4}$ Hyperphagia is usually complicated with altered eating habits, inadequate eating behaviors, and pica; this may easily lead to risks of upper airway obstruction, nutritional imbalance, or poisoning caused by erroneous eating and also increase the conflicts between caregivers and patients. ${ }^{4-8}$

The literature shows that the hyperphagic behaviors of patients with dementia may originate from damage to the frontotemporal lobe or an impaired satiety center 
in the ventromedial nucleus of the hypothalamus, thereby stimulating the neurological effects of starvation, or increasingly agitated behavior of patients with dementia, thereby requiring constant feeding to supplement calories. ${ }^{6,79,10}$ However, reports have also suggested that hyperphagia in patients with dementia is caused by memory degradation, which causes the patients to forget what food they have eaten or how to take the food accurately. ${ }^{11}$

Non-declarative memory (sometimes termed as implicit memory) has always been the focus of dementia memory training. It is involved with the unconscious recognition of an object (eg, priming) and the correct completion of the steps in a task (eg, procedural memory). Some studies found that individuals in the mild or moderate stages of Alzheimer's disease (AD) show improvement in non-declarative tasks. ${ }^{12-14}$ In this sense, interventions in patients with $\mathrm{AD}$ have the potential to maintain function through changed speed or accuracy when completing a task. Two approaches that can be used for training non-declarative memory are spaced retrieval (SR) and Montessori-based activities. ${ }^{15,16}$

$\mathrm{SR}$ is a learning approach developed to facilitate recall of a variety of information in individuals with dementia. When learning using SR, the patient repeatedly rehearses and recalls the information to be learnt at set intervals, with the interval between rehearsals constantly increasing. ${ }^{17-19}$ If the patient can still accurately recall information after more than 16 minutes, the information is considered to be successfully stored in their long-term memory system..$^{20}$ Creighton et al concluded Camp previous reported that the technique integrates four different methods of learning. ${ }^{21}$ First, SR is a form of "ecologically valid priming," whereby previous exposure to a stimulus influences later detection and identification of that stimulus. Second, SR is also believed to use "spacing effect" information that is learned and retrieved more effectively when trials are distributed over time rather than mass practiced. The utilization of both these methods is believed to be particularly beneficial to individuals with dementia, as they capitalize on relatively spared and automatic implicit memory system. Third, SR is regarded as a form of conditioning; strong associations are formed between the target question and response through repetition, and successful recall trials may serve as intrinsic reinforcers. Finally, SR can also be considered a form of errorless learning, as it minimizes the possibility of errors during the acquisition phase of learning by ensuring that mistakes are repeatedly corrected. ${ }^{22,23}$

de Ajuriaguerra and Tissot observed that decline of certain capacities in dementia appeared to reverse Piaget's developmental stages. ${ }^{24}$ Cognition and behavior development in children and loss in people with dementia were found to be remarkably similar. The cognitive capability of most elders with dementia has deteriorated to the preoperational stage (which is similar to mild and moderate dementia) or the sensorimotor stage (which is similar to severe dementia) of Piaget's theory of cognitive development. ${ }^{25}$ Piaget's theory also provides direction for the selection of appropriate activities to foster the development of cognitive skills at various ages by programmed Montessori-based activities. All Montessori-based activities, which were originally used with children aged 0-6 years, can break down each step of activities of daily living in order to enhance the procedural memory. Moreover, these activities can also provide sensory stimulation and movement coordination training to help the person with dementia to have a successful experience and create more control of behaviors within an orderly environment. ${ }^{25,26}$

Both SR and Montessori activities have been verified to alleviate the cognitive degeneration of patients with dementia, improve problem behaviors, and increase positive emotions and activities of daily living. ${ }^{23,27-29}$ Lin et al successfully used SR and Montessori-based activities to improve eating difficulties in patients with dementia, and $\mathrm{Wu}$ et al found that applying standardized and individualized SR in combination with Montessori activities training could significantly improve eating difficulties in patients with dementia. ${ }^{30,31}$ The causes of eating difficulties in patients with dementia are similar to those of hyperphagia, including impaired functioning of the satiety center of hypothalamus, which causes patients to forget how to take, chew, and swallow food, as well as worsening the ability to use tableware. However, the memory training processes in these studies involved using food as the teaching material and provided the participants with food they enjoyed as a reward after the end of each training period. During the process of behavior shaping, the provision of food items that patients like reinforces the learning process. Repeated provision of highly reinforcing food (especially food with a high sugar and fat content) can reinforce the social pleasure of the patients receiving training and constantly reinforce their behavior. ${ }^{32-34}$ The aim of this study was to investigate and compare the long-term effectiveness of SR and SR + M on improving hyperphagic behaviors of special care unit residents with dementia. This was to establish whether memory training can still improve abnormal behaviors of patients with dementia without the reinforcement of food and to investigate the difference in improvement of eating-related behaviors between SR alone and SR training combined with Montessori-based activities 
$(\mathrm{SR}+\mathrm{M})$. Further, this study was to understand whether Montessori activities in combination with SR can improve the effectiveness of message memorization.

\section{Methods}

\section{Participants}

The participants were recruited from eight dementia special care units in Taiwan, Republic of China (four longterm care facilities and four veterans' nursing homes). The inclusion criteria were as follows: 1) a diagnosis of dementia by a physician; 2) hyperphagia-related behavior scoring of at least 3 points on the scale used; 3 ) successfully clearing the SR screening test and the ability to maintain memory for 20 seconds; 4) able to see, listen, and read; and 5) possessing sufficiently fine hand movement and muscle power, scoring 4-5 points on the scale used. The exclusion criteria were as follows: 1) placed with a feeding tube or needing to be fed, 2) a body mass index of $<18.5 \mathrm{~kg} / \mathrm{m}^{2}$, 3) vascular dementia, or 4) a recent brain injury or acute gastrointestinal infection.

The study was reviewed and approved by Taipei City Hospital Institutional Review Board (TCHIRB No: 991226-E). A researcher personally explained the research and its purpose to institutional agents and family members and obtained their written informed consent (Trial registration: ChiCTR-IOR-15007531).

\section{Study design}

This study had a longitudinal two-step cluster-randomized single-blind design and was conducted from June 2012 to October 2014. After the institutions identified research subjects who met the inclusion criteria, trained research assistants collected pretest data of all the subjects and classified the severity of their hyperphagia as mild, moderate, or severe. The patients in each hyperphagia category were randomized into three groups, and a homogeneity test was applied to confirm that these groups were homogeneous. The patients were then randomly assigned to the SR group (48 subjects), the SR + M group (52 subjects), and the control group (48 subjects).

After the grouping of subjects was confirmed, two memory trainers who had received training in SR and Montessori activity methods provided the two experimental groups with memory training courses for a total of 30 sessions spread over 6 consecutive weeks (with each session lasting for at least 40 minutes). The control group did not receive any intervention but instead engaged in the routine activities of institutions. Following completion of the interventions, the research assistants collected post-training test data and follow-up data at 1 month, 3 months, and 6 months for the subjects in all the three groups. During the research process, a total of eight subjects left the study (SR group: 2; SR + M group: 3 ; control group: 3 ). The main causes were hospitalization (five subjects), returning home for care (two subjects), and death (one subject). A total of 140 subjects completed the entire research process and follow-up data collection, including 46 subjects in the SR group, 49 in the SR + M group, and 45 in the control group (Figure 1).

\section{Interventions}

Four training objectives were set and 30 sessions designed. The objectives for the subjects were as follows: 1) to memorize where food is placed (only food placed in bowls could be taken: four sessions); 2) to memorize slowing down their dining speed (chewing slowly, swallowing slowly, and eating the food bite by bite: eleven sessions); 3) to memorize a satiation message (stopping eating on hearing a 20 -second melody and putting down the bowl: eight sessions) - the 20 -second melody functions as a warning message to remind the patients with dementia to stop eating when hearing it; in addition to being applied in classroom training, it was also played 40 minutes after three meals throughout the course of the 6-week intervention to enable all the residents to hear it; however, it was no longer played after the 6 weeks were up - and 4) to memorize appropriate dining etiquette behavior (appropriate behavior while eating and interacting with other people: seven sessions). Each session was held in a room in the dementia special care units. Trainers began by introducing themselves to the subjects for reorientation and then gave the memory training, after which they provided a review of the session. Each session lasted for at least 40 minutes. The memory training process of each group was as follows:

1. The SR group: During each training session, the subject had to learn (and review) a memory message. Once they could successfully recall the message immediately ( 0 minute), the trainer extended the time before recalling the message to 1 minute; if the subject still could remember the message, the recall interval was extended sequentially to 2 minutes, 4 minutes, 6 minutes, 8 minutes, and 16 minutes. If the subject forgot the message, the trainer retrained them to memorize it and returned to the previous recall interval for the subject to recall the message again and then adjusted the memory training interval backwards or forwards according to the subject's recall performance until the end of the training. At the end of the session, the trainer recorded the subject's longest 


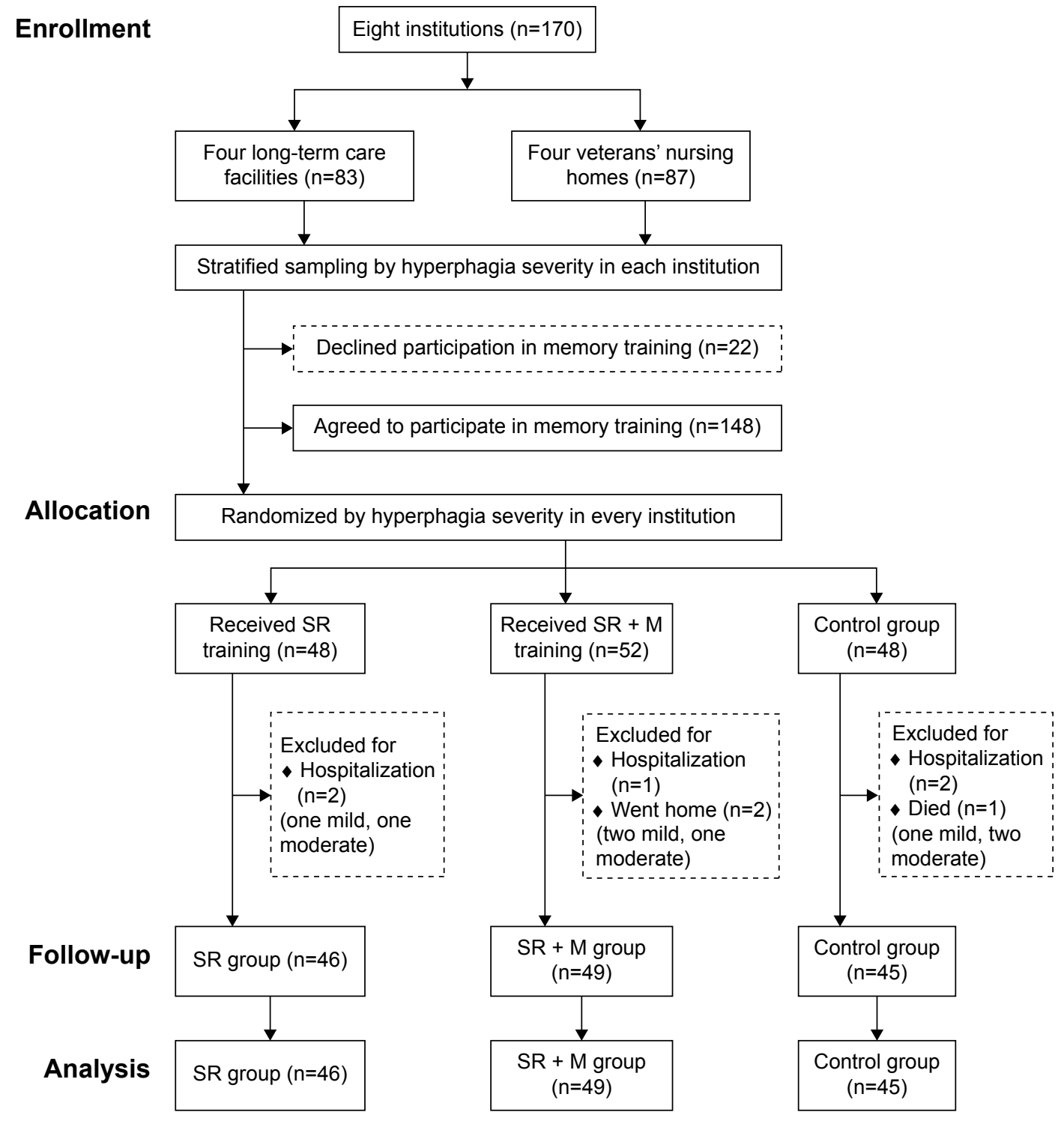

Figure I Flow diagram of the study according to the CONSORT statement.

Abbreviations: CONSORT, Consolidated Standards of Reporting Trials; SR, spaced retrieval training group; SR + M, spaced retrieval and Montessori-based activities training group.

recall interval. The training sessions that continued with the same objective started with the longest recall interval of the previous session; training sessions beginning a new objective started with a recall interval of 0 minute. When the subject failed to immediately recall a message, the trainer provided auxiliary memory clues, such as images or texts, one by one. During the recall interval, the trainers arranged interesting nonstructured activities for the subjects, such as drawing, reading a newspaper, or poker games (the example is given in Table S1 and Figure S1).

2. The $\mathrm{SR}+\mathrm{M}$ group: The same procedure described for SR memory training was followed; however, in this group, the subjects engaged in action and practice-based structured Montessori activities during the recall interval. Each activity started with sensory stimulation followed by practicing an action (eg, gently pressing, scooping, or aligning) using standard procedure and the cognitive training of matching and identification. The same Montessori activity teaching aids were used throughout the process. Trainers could adjust the complexity of activities according to the subject's learning condition (the example is given in Table S1 and Figure S1).

3. The control group: The control group engaged in the routine activities of institutions, with no particular memory training activities. 


\section{Measures}

\section{Demographic characteristics}

In addition to collecting demographic information on age, sex, education, marital status, length of institutionalization, duration of dementia, and family visits, Chinese versions of Mini-Mental State Examination (MMSE) and recall subscale of the MMSE, Barthel index, and Cohen-Mansfield Agitation Inventory were also used to evaluate separately the episodic memory, functional status, and 29 agitated behaviors of subjects because of their good internal consistency, interrater reliability, and concurrent validity. ${ }^{35-37}$

\section{Scale of hyperphagia in residents with dementia}

A convenience sample of 21 formal and informal caregivers from day care centers and long-term care facilities were interviewed to determine excessive eating behaviors among elders with dementia. The interview guide included what eating behaviors change the caregiver observed such as increasing eating frequency, preferred food, searching food, etc.; how the caregiver felt and responded for the abovementioned behaviors as well as managed those behaviors. The interview took 50-90 minutes. The interviews were tape-recorded and then transcribed. Content analysis was used to analyze the interview data. A 19-item scale of hyperphagia in residents with dementia and a ten-item scale of distress of the caregiver to hyperphagic behaviors were categorized from the interviews. Content validity index for five experts in first time was 0.870 , because one expert disagreed that pica was included in excessive eating behaviors. After obtaining the expert's agreement about "the definition of excessive eating may be a variant of hyperorality disturbances which include oral exploration and pica," consistency, Cronbach's alpha was 0.918. To determine interrater reliability, intraclass coefficient was $0.793-0.796{ }^{38}$

To evaluate hyperphagic behaviors, each subject was observed for 7 consecutive days, including observations of at least ten lunch or dinner dining situations. A 19-item "scale of hyperphagia in residents with dementia" was used to facilitate this. ${ }^{32}$ The scale covered four categories' behaviors: intention to eat, rapid eating, increased eating, and inappropriate dining etiquette. The observed frequencies for each of these hyperphagic behaviors were scored as follows: the subject did not engage in the hyperphagic behavior, 0 points; one to three occurrences, 1 point; four to six occurrences, 2 points; and more than seven occurrences, 3 points. If the score for a single behavior was 3 points or more or the total score exceeded 3 points, the subject was considered suffering from hyperphagia. The severity of hyperphagia was determined from the total score: 3 points, mild hyperphagia; 4-6 points, moderate hyperphagia; $>7$ points, severe hyperphagia. The internal consistency (Cronbach's $\alpha$ ) and the interrater reliability (intraclass correlation coefficient) of this scale were 0.91 and 0.92 , respectively. ${ }^{38}$ During the observation period, record forms were also used to collect information on pica, changes in eating habits, and short meal frequency. Pica was scored as "yes" (1 point) or "no" ( 0 point) according to whether the subjects ate food that was inedible (eg, soap or stone) or inappropriate (eg, raw meat, food waste, or spoiled food). The changes in eating habits assessed using record forms covered eight types of changes (eg, prefer sweet foods more than before and tend to eat food in the same order). The short meal frequency form was used to record the frequency of meals that lasted for $<10$ minutes.

All the observation records were collected by six research assistants who had cleared the 24-hour observer training and completed an interrater reliability test. The research assistants were blinded to the randomization of subjects. To avoid the Hawthorne effect during the collection of observation data, this study used 6-8 subjects on the same table as that of the special care unit to perform regional, positional, and whole-day observation, instead of observing the subjects only at meal times in the observation area.

\section{Scale of distress of the caregiver to hyperphagic behaviors}

Primary caregivers in the institutions were invited to complete a "scale of distress of the caregiver to hyperphagic behaviors." Reactions to each of ten hyperphagic behaviors (eg, "I' $m$ bothered that residents keep asking for food when I didn't provide them with it"; "I'm worried that residents eat what they should not eat") were scored on a Likert scale (0-3) according to the level of distress. Higher scores indicated higher distress due to hyperphagic behavior to the caregiver. The content validity index for five experts was 1 . The internal consistency was shown to be $0.706 .{ }^{38}$

\section{Statistical analysis}

SPSS for Windows Version 20.0 was used for the statistical analysis, and $P$-values $<0.05$ were considered significant. Generalized estimating equation was used to analyze the changes from the pretraining test data in the post-training test and 1-month, 3-month, and 6-month follow-up data for all three groups of subjects. Differences between the two experimental groups in the performance of memory training were evaluated with independent sample $t$-tests, the Friedman test, and the Wilcoxon signed-rank test. 


\section{Results}

The mean age of the 140 research subjects was 82.55 years (standard deviation [SD]: 5.95), and 70.7\% of them were men. The educational background of most of the subjects was attending up to high school. The subjects mainly suffered from moderate cognitive impairment, mild dysfunction in daily activities, and mild agitation (MMSE score: 12.09, SD: 5.15; Barthel index: 67.25, SD: 24.90; Cohen-Mansfield Agitation Inventory score: $39.51, \mathrm{SD}: 7.03)$. The mean duration of stay in institutions was 3 years, which was also the mean time since the confirmation of diagnosis of dementia. Most subjects were married. The family members and friends of $54.3 \%$ of the subjects visited them at least once every month. The homogeneity test on the three groups showed no significant differences among the groups (Table 1).

This study used a generalized estimating equation to compare all the 6-month follow-up data of the three groups. The results showed that the scores of the SR group for hyperphagic behavior and pica continued to decrease for
3 months and the improvement in short meal frequency lasted for 1 month after memory training. For the $\mathrm{SR}+\mathrm{M}$ group, the improvements in hyperphagic behavior and short meal frequency lasted for 6 months after training. The improvement in distress to the primary caregiver of both the SR and $\mathrm{SR}+\mathrm{M}$ groups only lasted until the post-training test. There was no significant change in eating habits among the three groups (Table 2).

Analyses of the effectiveness of improvement in frequency of the four categories behaviors of hyperphagia (intention to eat, rapid eating, increased eating, and inappropriate dining etiquette) show that the behaviors of "rapid eating" and "increased eating" improved in both the SR and $\mathrm{SR}+\mathrm{M}$ groups. The improvement lasted for a longer period of time in the SR + M group (Table 3).

In memory performance, after 30 session's activity intervention, the recall scores on the MMSE in posttest was slightly higher than pretest in both experimental groups, while the recall scores on the MMSE in the posttest was lower

Table I Demographic data $(\mathrm{N}=\mid 40)$

\begin{tabular}{|c|c|c|c|c|c|c|c|c|c|c|}
\hline \multirow[b]{3}{*}{ Age } & \multirow{2}{*}{\multicolumn{2}{|c|}{$\frac{\text { All }(n=\mid 40)}{\text { Mean } \pm \text { SD }}$}} & \multirow{2}{*}{\multicolumn{2}{|c|}{$\begin{array}{l}\text { SR }(n=46) \\
\text { Mean } \pm \text { SD }\end{array}$}} & \multirow{2}{*}{\multicolumn{2}{|c|}{$\frac{S R+M(n=49)}{M e a n \pm S D}$}} & \multirow{2}{*}{\multicolumn{2}{|c|}{$\frac{\text { Control group }(n=45)}{\text { Mean } \pm \text { SD }}$}} & \multirow{3}{*}{$\begin{array}{l}F^{\mathrm{a}}, * \\
0.550\end{array}$} & \multirow{3}{*}{$\begin{array}{l}\text { P-value, }{ }^{*} \\
0.578\end{array}$} \\
\hline & & & & & & & & & & \\
\hline & 82.55 & 5.95 & 83.10 & 5.00 & 82.69 & 6.81 & 81.82 & 5.89 & & \\
\hline MMSE score & 12.09 & 5.15 & 12.33 & 5.41 & 12.08 & 4.05 & 11.84 & 5.49 & 0.098 & 0.907 \\
\hline Barthel index & 67.25 & 24.90 & 67.17 & 24.14 & 66.84 & 25.97 & 67.78 & 25.03 & 0.017 & 0.983 \\
\hline CMAl score & 39.51 & 7.03 & 39.36 & 8.67 & 39.79 & 7.23 & 39.35 & 4.73 & 0.060 & 0.942 \\
\hline Length of institution (month) & 35.98 & 32.43 & 34.30 & 33.84 & 38.39 & 30.48 & 35.07 & 33.59 & 0.212 & 0.809 \\
\hline \multirow[t]{2}{*}{ Duration of dementia (month) } & 37.35 & 31.75 & 33.20 & 32.75 & 40.06 & 31.83 & 38.80 & 30.79 & 0.610 & 0.545 \\
\hline & $\mathrm{n}$ & $\%$ & $\mathbf{n}$ & $\%$ & $\mathbf{n}$ & $\%$ & $\mathbf{n}$ & $\%$ & $\chi^{2, \mathrm{~b}}$ & \\
\hline Sex & & & & & & & & & 1.422 & 0.491 \\
\hline Female & 41 & 29.3 & 13 & 28.3 & 12 & 24.5 & 16 & 35.6 & & \\
\hline Male & 99 & 70.7 & 33 & 71.7 & 37 & 75.5 & 29 & 64.4 & & \\
\hline Education & & & & & & & & & 7.023 & 0.723 \\
\hline Illiterate & 36 & 25.7 & 14 & 30.4 & 9 & 18.4 & 13 & 28.9 & & \\
\hline Primary school & 39 & 27.9 & II & 23.9 & 13 & 26.5 & 15 & 33.3 & & \\
\hline High school & 43 & 30.7 & 14 & 30.4 & 17 & 34.6 & 12 & 26.7 & & \\
\hline$\geq$ College & 22 & 15.7 & 7 & 15.2 & 10 & 20.4 & 5 & II.I & & \\
\hline Marital status & & & & & & & & & 3.618 & 0.890 \\
\hline Unmarried & 25 & 17.9 & 8 & 17.4 & 9 & 18.4 & 8 & 17.8 & & \\
\hline Married & 53 & 37.9 & 21 & 45.7 & 15 & 30.6 & 17 & 37.8 & & \\
\hline Widowed/widower & 50 & 35.7 & 13 & 28.3 & 20 & 40.8 & 17 & 37.8 & & \\
\hline Divorced & 12 & 8.5 & 4 & 8.7 & 5 & 10.2 & 3 & 6.7 & & \\
\hline Family visits & & & & & & & & & 7.595 & 0.816 \\
\hline None & 23 & 16.4 & 7 & 15.2 & 10 & 20.4 & 6 & 13.3 & & \\
\hline Once every 6 months & 13 & 9.3 & 4 & 8.7 & 5 & 10.2 & 4 & 8.9 & & \\
\hline Once every 4-6 months & 11 & 7.9 & 4 & 8.7 & 6 & 10.2 & I & 2.2 & & \\
\hline Once every I-3 months & 17 & 12.1 & 6 & 13.0 & 3 & 6.1 & 8 & 17.8 & & \\
\hline I-2 times per month & 36 & 25.7 & 12 & 26.1 & 13 & 26.5 & II & 24.4 & & \\
\hline Several times per week & 40 & 28.6 & 13 & 28.2 & 12 & 24.5 & 15 & 33.3 & & \\
\hline
\end{tabular}

Notes: ${ }^{a}$ One-way ANOVA analysis; ' chi-square test. *There are no significant differences among three groups.

Abbreviations: ANOVA, analysis of variance; MMSE, Mini-Mental State Examination; CMAl, Cohen-Mansfield Agitation Inventory; SD, standard deviation; SR, spaced retrieval training group; SR + M, spaced retrieval combined with Montessori-based activities training group. 


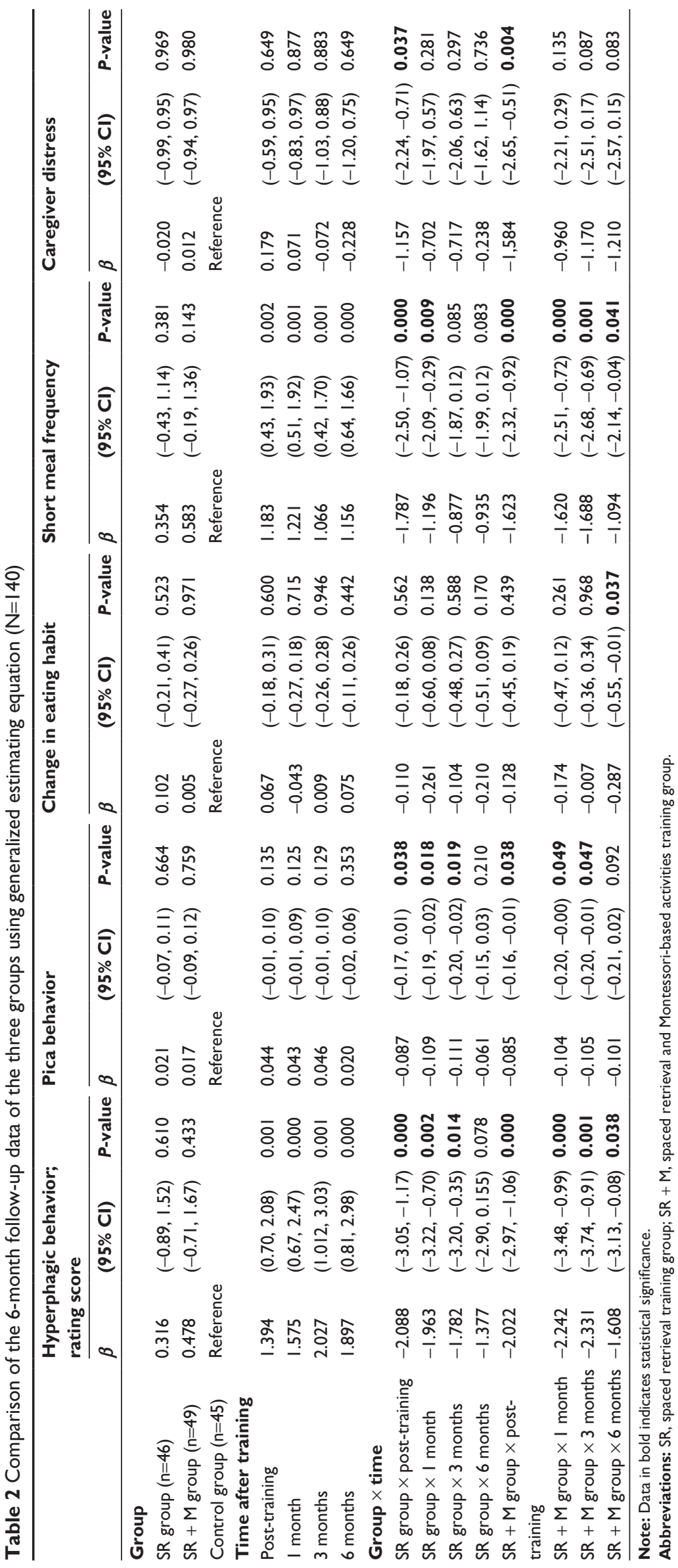




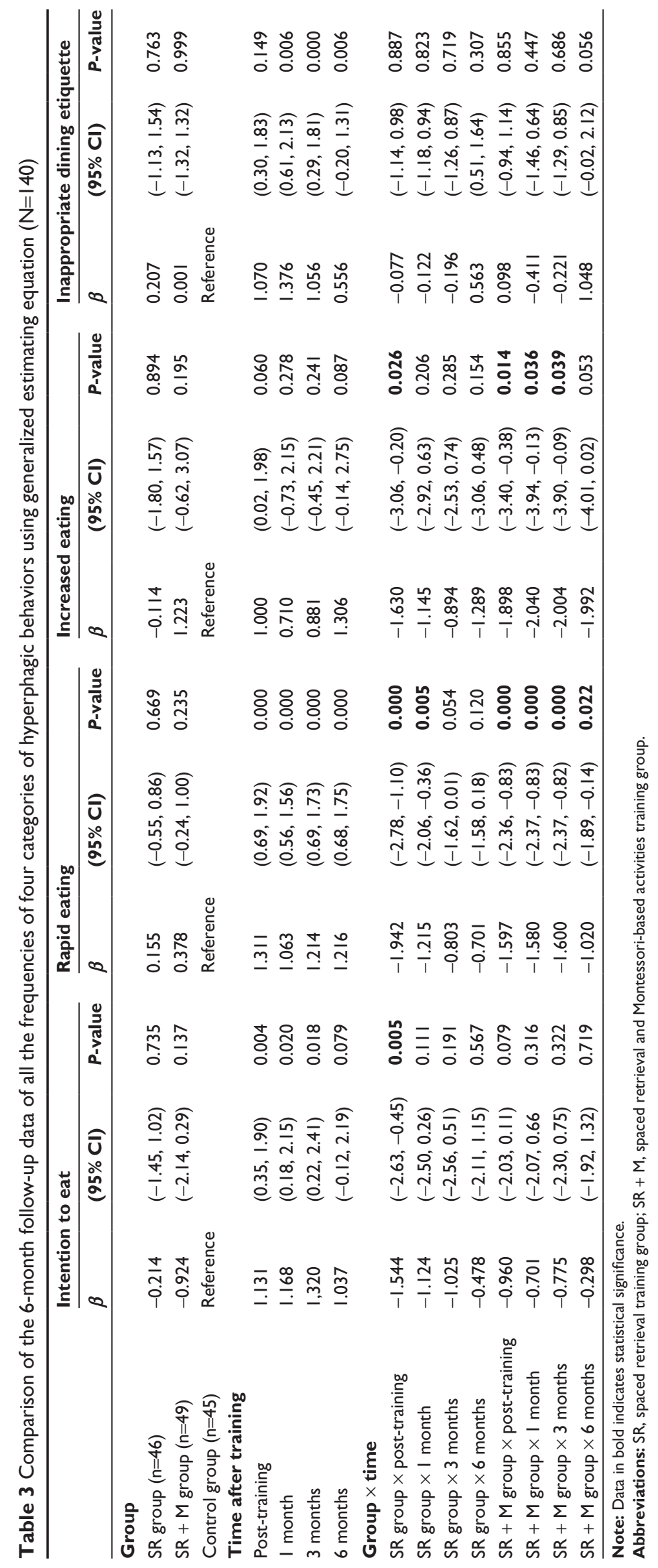


Table 4 Comparison of the 6-month follow-up data of recall scores on the MMSE among the three groups using generalized estimating equation $(\mathrm{N}=\mid 40)$

\begin{tabular}{|c|c|c|c|}
\hline & \multicolumn{3}{|l|}{ Recall } \\
\hline & $\beta$ & $(95 \% \mathrm{Cl})$ & $P$-value \\
\hline \multicolumn{4}{|l|}{ Group } \\
\hline SR group $(n=46)$ & -0.297 & $(-0.62,0.03)$ & 0.077 \\
\hline$S R+M$ group $(n=49)$ & -0.258 & $(-0.59,0.07)$ & 0.129 \\
\hline Control group $(n=45)$ & Reference & & \\
\hline \multicolumn{4}{|l|}{ Time after training } \\
\hline Post-training & -0.244 & $(-0.45,-0.32)$ & 0.024 \\
\hline I month & -0.356 & $(-0.56,-0.14)$ & 0.001 \\
\hline 3 months & -0.383 & $(-0.59,-0.16)$ & 0.000 \\
\hline 6 months & -0.407 & $(-0.62,-0.19)$ & 0.000 \\
\hline \multicolumn{4}{|l|}{ Group $\times$ time } \\
\hline SR group $\times$ post-training & 0.310 & $(0.01,0.60)$ & 0.042 \\
\hline SR group $\times$ I month & 0.334 & $(0.03,0.63)$ & 0.028 \\
\hline SR group $\times 3$ months & 0.264 & $(-0.04,0.56)$ & 0.085 \\
\hline SR group $\times 6$ months & 0.288 & $(-0.01,0.59)$ & 0.061 \\
\hline$S R+M$ group $\times$ post-training & 0.306 & $(0.01,0.59)$ & $0.04 I$ \\
\hline$S R+M$ group $\times I$ month & 0.362 & $(0.06,0.66)$ & 0.016 \\
\hline$S R+M$ group $\times 3$ months & 0.325 & $(0.02,0.63)$ & 0.034 \\
\hline$S R+M$ group $\times 6$ months & 0.304 & $(0.01,0.60)$ & 0.047 \\
\hline
\end{tabular}

Note: Data in bold indicates statistical significance.

Abbreviations: SR, spaced retrieval training group; $S R+M$, spaced retrieval and Montessori-based activities training group.

than pretest in the control group. However, SR and SR + M training programs can improve recall memory performance of patients with dementia that lasted for at least 1 month after training (Table 4).

The longest recall intervals in the sessions associated with training objectives 1,2 , and 3 were better than those for the sessions for training objective 4 (to memorize appropriate dining etiquette behavior) in both groups. The best recall performance in both groups was during sessions for training objective 2 (to memorize slowing down the dining speed); the performance of the SR + M group was significantly better than that of the SR group ( $t=2.052, P=0.044)$, particularly in the training for "chewing slowly" ( $t=3.018$, $P=0.004$; Table 5).

\section{Discussion}

Lee et al examined whether SR training could improve cognitive function in people with very mild to mild dementia, but no change in neuropsychological performance was found. ${ }^{39}$ It was believed that factors leading to this result included a low cognitive effort required for SR training, and the small sample size of their study. In the current study, we combined SR with accumulating cues and Montessori-based activities to create an effortful learning condition. We found the same increase in performance on recall memory scores as did $\mathrm{Wu}$ et al, ${ }^{40}$ who indicates that applying the SR with accumulating techniques were more likely to at least possibly maintain memory status. Although the change in recall memory scores in both experimental groups did not reach statistical significance in the subsequent three follow-ups, there was a trend toward significant improvement. On the other hand, this study found that both the SR and SR + M memory training can improve the hyperphagic behavior of patients with dementia without the need for food incentives. This finding is consistent with that of the study by Lin et $\mathrm{al}^{30}$ and $\mathrm{Wu}$ et al, ${ }^{31}$ suggesting that SR and Montessori activities can improve dysphagia of patients with dementia. The longest recall interval of subjects participating in this study was 31 minutes, which is almost the same as that of patients with dementia in studies by Lee et al and Wu et al. ${ }^{39,40}$ Thus, non-declarative memory training can be used for patients with moderate dementia, and it can help improve eating behaviors of patients with dementia. ${ }^{12,26,41,42}$ Even though this study revealed positive effects of memory training, every patient with hyperphagia had to receive 40 minutes of memory training, five times per week for a total of 30 times. The caregivers could confirm the suitable time for the daily training of patients with dementia and then referred to the protocols designed in this study to provide one-on-one memory training.

The training results showed that the hyperphagic behaviors that were significantly improved were rapid eating, increased eating, and pica. All these behaviors can affect the dietary safety of patients with dementia and lead to conflicts between them and with others. For example, rapid eating may involve swallowing food without chewing, stuffing the mouth with food without swallowing, and eating quickly when seeing food. Similarly, increased eating includes stealing food from other's plate, eating on seeing food, and eating continually in the presence of food without a sensation of being full, and pica behavior involves eating inedible or inappropriate food. The results of this study suggest that the reason for the improvement of these specific behaviors was that the relevant training was provided in earlier training sessions (on knowing where the food is and slowing down the dining speed). It could be expected that the subjects would have relatively greater cumulative memories of these. Moreover, both rapid eating and pica behavior involved more specific actions and behaviors, and therefore, it was easier for patients with dementia to firmly memorize the associated training. The other two behaviors - intention to eat and dining etiquette - involved greater psychological and interactive 


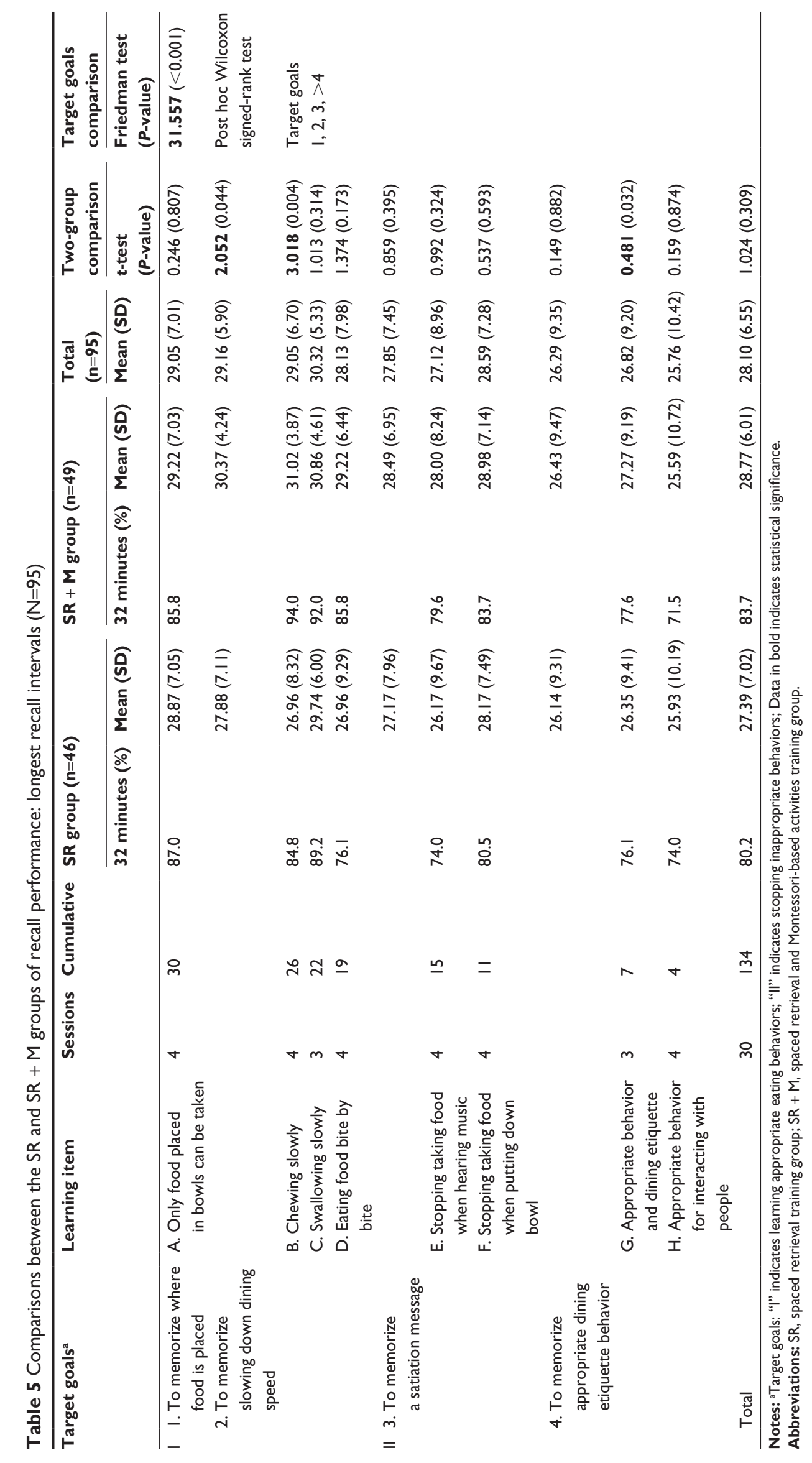


learning, particularly with dining etiquette; therefore, it was more difficult for patients with moderate dementia to memorize and learn them. This was supported by the results of the longest recall intervals, which were lowest for the sessions about dining etiquette. Therefore, if the inadequate behaviors of patients with dementia are deconstructed (breaking tasks into small components and starting with easier items), it will be easier for improvement by providing continuous training for specific actions. ${ }^{43}$

Montessori activities are structured activities that involve everyday practical tasks and engage the learning-by-doing system, thus it can provide patients with dementia with the continuous practice required by procedural memory. Beyond that, these activities are designed with rich, tangible sensory stimulation to improve patient's motor coordination, sense of reality, and sense of control over surroundings. ${ }^{16,44,45}$ Therefore, Montessori activities are beneficial for learning in patients with dementia, which was reflected in our study results: the slowing down of dining speed was significantly better in the SR + M group than in the SR group, and the improvements in dining speed and short meal frequency also lasted longer in the SR + M group.

The baseline scores for caregiver distress for the three groups of subjects were not high. The reason for this may be that the Chinese believe that being able to eat is a blessing, and therefore, they usually encourage the elderly to eat food; they would have greater concerns about elderly people eating too little rather than too much. A previous survey showed that one-third of caregivers worry about swallowing problems. ${ }^{46}$ However, compared with dysphagia, the Chinese are more tolerant toward hyperphagia, and their perceived distress regarding hyperphagia was lower. ${ }^{47}$ Therefore, there was little scope to improve on caregiver distress. Moreover, the subjects were able to eat by themselves. With memory training, once the problem of short meal times was improved, the meal time of a greater number of patients with dementia increased, which would in turn be expected to increase the need for the company of caregivers or the provision of dining assistance. ${ }^{30}$ This may be the reason why the distress of caregivers was not continuously improved.

After memory training, there was no significant change in eating habits in the three groups. Changes in eating habits are more common in patients with frontotemporal dementia or severe semantic dementia and may also be associated with hallucinations, change in taste perception, or antipsychotic drugs used to treat severe agitated behaviors. ${ }^{10,11,48-50}$ This study mainly enrolled patients with AD who had fewer behavioral and psychiatric symptoms and moderate cognitive impairment. The total baseline score for changes in eating habits was not high. Moreover, it cannot be ignored that dementia special care units usually provide regular meals in a closed environment, and therefore, it is less likely that patients independently acquire or choose food. Therefore, the obtainment of food source and change in eating habits of the subjects may be affected, leading to no significant difference among the three groups.

\section{Limitations}

This retrospective study, unlike investigational studies, used behavioral observation to collect and analyze long-term data. However, some limitations are acknowledged in this study. First, the subjects were recruited from eight dementia special care units in Taiwan, Republic of China, and therefore, the research result may only be generalized to Taiwanese residents with dementia who live in dementia special care units. Second, due to the limitations of the institutionalized meal supply culture (a fixed amount of food is provided at a fixed time or the food source is strictly limited), it could be expected that the observed hyperphagic behaviors of residents with dementia were underestimated. However, conversely, these factors also enabled subjects to continue maintaining stable dining during the intervention process. The effect of memory training programs on improving hyperphagic behavior of patients with dementia living in a community should be explored further. Finally, eating problems involve extremely complex factors, including physiological and psychological factors, and aspects of interpersonal interaction. This study focused on behavioral observation and improvement. Future studies should collect other relevant data in multiple ways to confirm the full impact of memory training on hyperphagia of patients with dementia.

\section{Conclusion}

Restricting or prohibiting a certain behavior tends to induce frustration or anger in patients with dementia. Therefore, the training in this study did not focus on restricting the food intake of patients with dementia but on improving hyperphagic behaviors instead. The training programs were integrated with real situations to simulate dining procedures. From starting to eat food to slowing down the dining speed, learning to memorize satiation messages, and exhibiting appropriate dining etiquette, daily training enabled residents with dementia to constantly review and gradually adjust their inappropriate behaviors and relearn to accurately and slowly consume the amount of food they were supposed to eat. 
This study found that SR and SR + M memory training were non-pharmacological interventions that could improve hyperphagic behaviors of patients with dementia and significantly improve rapid eating, increased eating, and pica behavior. When patients with dementia exhibit the hyperphagic problem of rapid eating, $\mathrm{SR}+\mathrm{M}$ memory training is advised for long-term effectiveness. Caregivers can choose suitable training programs according to the eating problems of their residents.

\section{Acknowledgments}

This study was funded by the Ministry of Science and Technology of Taiwan (NSC99-2628-B-010-016-MY3). The authors thank all participating institutions who gave their utmost cooperation in completing this study. The authors also thank all the research assistants involved during the data collection period.

\section{Author contributions}

LCL obtained funding. CCK and LCL were responsible for overall study design. All authors contributed toward data analysis, interpretation of the data, and drafting and revising the paper and agree to be accountable for all aspects of the work.

\section{Disclosure}

The authors report no conflicts of interest in this work.

\section{References}

1. Keene JM, Hope T. Natural history of hyperphagia and other eating changes in dementia. Int J Geriatr Psychiatry. 1998;13:700-706.

2. Wu HS. Predictors of hyperphagia in institutionalized patients with dementia. J Nurs Res. 2014;22:250-258.

3. Keene JM, Hope T. The microstructure of eating in people with dementia who are hyperphagic. Int J Geriatr Psychiatry. 1996;11:1041-1049.

4. Keene JM, Hope T. Hyperphagia in dementia: 1. the use of an objective and reliable method for measuring hyperphagia in people with dementia. Appetite. 1997;28:151-165.

5. Hsiao HC, Chao HC, Wang JJ. Features of problematic eating behaviors among community-dwelling older adults with dementia: family caregiver's experience. Geriatr Nurs. 2013;34:361-365.

6. Morris $\mathrm{CH}$, Hope RA, Fairburn CG. Eating habits in dementia a descriptive study. Br J Psychiatry. 1989;154:801-806.

7. Smith G, Vigen V, Evans J, Fleming K, Bohac D. Patterns and associates of hyperphagia in patients with dementia. Neuropsychiatry Neuropsychol Behav Neurol. 1998;11:97-102.

8. Trinkle DB, Burns A, Levy R. Brief report: abnormal eating behavior in dementia a descriptive study. Int J Geriatr Psychiatry. 1992;7: 799-803.

9. Greenwood CE, Tam C, Chan M, Young KWH, Binns MA, van Reekum R. Behavioral disturbances, not cognitive deterioration, are associated with altered food selection in seniors with Alzheimer's disease. J Gerontol A Biol Sci Med Sci. 2005;60:499-505.

10. Ikeda M, Brown J, Holland AJ, Fukuhara R, Hodges JR. Changes in appetite, food preference, and eating habits in frontotemporal dementia and Alzheimer's disease. J Neurol Neurosurg Psychiatry. 2002;73: 371-376.
11. Fairburn CG, Hope RA. Changes in eating in dementia. Neurobiol Aging. 1988;9:28-29.

12. Fleischman DA, Wilson RS, Gabrieli JD, Schneider JA, Bienias JL, Bennett DA. Implicit memory and Alzheimer's disease neuropathology. Brain. 2005;128:2006-2015.

13. Golby A, Silverberg G, Race E, et al. Memory encoding in Alzheimer's disease: an fMRIstudy of explicit and implicit memory. Brain. 2005; 128:773-787.

14. Mahendra N, Apple A. Human memory systems: a framework for understanding dementia. ASHA Lead. 2007;12:8-11.

15. Hopper T, Mahendra N, Kim E, et al. Evidence-based practice recommendations for working with individuals with dementia: spaced-retrieval training. J Med Speech Lang Pathol. 2005;13(4):xxvii-xxxiv.

16. Mahendra N, Scullion A, Hamerschlag C. Cognitive-linguistic interventions for persons with dementia. Top Geriatr Rehabil. 2011;27: 278-288.

17. Brush JA, Camp CJ. A Therapy Technique for Improving Memory: Spaced Retrieval. Beachwood, OH: Menorah Park Center for the Aging; 1998.

18. Chapey R. Language Intervention Strategies in Aphasia and Related Neurogenic Communication Disorders. 5th ed. Philadelphia: Lippincott Williams \& Wilkins; 2008.

19. Hopper T, Bourgeois M, Pimentel J, Qualls CD, Hickey E, Frymark T. An evidence-based systematic review on cognitive interventions for individuals with dementia. Am J Speech Lang Pathol. 2013;22:126-145.

20. Vance DE, Farr KF. Spaced retrieval for enhanced memory: implications for nursing practice and research. J Gerontol Nurs. 2007;33:46-52.

21. Camp CJ. Spaced Retrieval: A Model for Dissemination of a Cognitive Intervention for Persons with Dementia. New York: The Guilford Press; 2006.

22. Haslam C, Hodder KI, Yates PJ. Errorless learning and spaced retrieval: how do these methods fare in healthy and clinical populations? J Clin Exp Neuropsychol. 2011;33:432-437.

23. Creighton AS, Van der Ploeg ES, O'Connor DW. A literature review of spaced-retrieval interventions: a direct memory intervention for people with dementia. Int Psychogeriatr. 2013;25(11):1743-1763.

24. de Ajuriaguerra J, Tissot R. Some aspects of psychoneurologic disintegration in senile dementia. In: Mueller CH, Ciompi L, editors. Senile Dementia. Bern:Huber; 1968:69-79.

25. Matteson MA, Linton AD, Barnes SJ, Cleary BL, Lichtenstein MJ. The relationship between Piaget and cognitive levels in persons with Alzheimer's disease and related disorders. Aging (Milano). 1996;8: 61-69.

26. Mahendra N, Hopper T, Bayles KA, Azuma T, Cleary S, Kim E. Evidence-based practice recommendations for working with individuals with dementia: Montessori-based interventions. J Med Speech Lang Pathol. 2006;14:xv-xxv.

27. Lin LC, Yang MH, Kao CC, Wu SC, Tang SH, Lin JG. Using acupressure and Montessori-based activities to decrease agitation for residents with dementia: a cross-over trial. J Am Geriatr Soc. 2009;57:1022-1029.

28. Sheppard CL, McArthur C, Hitzig SL. A systematic review of Montessori-based activities for persons with dementia. J Am Med Dir Assoc. 2015;14:15258610-15258643.

29. van der Ploeg ES, Eppingstall B, Camp CJ, Runci SJ, Taffe J, O'Connor DW. A randomized crossover trial to study the effect of personalized, one-to-one interaction using Montessori-based activities on agitation, affect, and engagement in nursing home residents with Dementia. Int Psychogeriatr. 2013;25:565-575.

30. Lin LC, Huang YJ, Su SG, Watson R, Tsai BW, Wu SC. Using spaced retrieval and Montessori-based activities in improving eating ability for residents with dementia. Int J Geriatr Psychiatry. 2010;25:953-959.

31. Wu HS, Lin LC, Wu SC, Lin KN, Liu HC. The effectiveness of spaced retrieval combined with Montessori-based activities in improving the eating ability of residents with dementia. $J A d v$ Nurs. 2014;70: 1891-1901.

32. Cooke LJ, Chambers LC, Anez EV, Wardle J. Facilitating or undermining? The effect of reward on food acceptance. A narrative review. Appetite. 2011;57:493-497. 
33. Epstein LH, Leddy JJ, Temple JL, Faith MS. Food reinforcement and eating: a multilevel analysis. Psychol Bull. 2007;133:884-906.

34. Lu J, Xiong S, Arora N, Dube L. Using food as reinforce to shape children's non-food behavior: the adverse nutritional effect doubly moderated by reward sensitivity. Eat Behav. 2015;19:94-97.

35. Yip PK, Shyu YI, Liu SI, et al. An epidemiological survey of dementia among elderly in an urban district of Taipei. Acta Neurol Sin. 1992;1:347-354.

36. Shah S, Vanclay F, Cooper B. Improving the sensitivity of the Barthel index for stroke rehabilitation. J Clin Epidemiol. 1989;42:703-709.

37. Lin LC, Kao CC, Tzeng YL, Lin YJ. Equivalence of Chinese version of the Cohen-mansfield agitation inventory. $J$ Adv Nurs. 2007;59 $178-185$.

38. Lin LC. Efficacy of Spaced Retrieval Training Program in Decreasing Overeat for Institutionalized Residents with Dementia. Taipei City: ROC: National Science Council; 2010. (Research grant NSC99-2628B-010-016-MY3).

39. Lee SB, Park CS, Jeong JW, et al. Effects of spaced retrieval training (SRT) on cognitive function in Alzheimer's disease (AD) patients. Arch Gerontol Geriatr. 2009;49:289-293.

40. Wu HS, Lin LC, Su SC, Wu SC. The effects of spaced retrieval combined with errorless learning in institutionalized elders with dementia: recall performance, cognitive status, and food intake. Alzheimer Dis Assoc Disord. 2014;28:333-339.

41. Machado S, Cunha M, Minc D, et al. Alzheimer's disease and implicit memory. Arq Neuropsiquiatr. 2009;67:334-342.

42. van der Ploeg ES, O'Connor DW. Evaluation of personalized, oneto-one interaction using Montessori-type activities as a treatment of challenging behaviours in people with dementia: the study protocol of a crossover trial. BMC Geriatr. 2010;10:1-6.
43. Camp CJ, Schneider N, Orsulic-Jeras S, et al. Montessori-Based Activities for Persons with Dementia. Beachwood, OH: Menorah Park Center for Senior Living; 2006:2.

44. Jarrott S, Gozali T, Gigliotti C. Montessori programming for persons with dementia in the group setting: an analysis of engagement and affect. Dementia. 2008;7:109-125.

45. Vance DE, Porter R. Montessori methods yield cognitive gains in Alzheimer's daycares. Act Adapt Aging. 2000;24:1-21.

46. Alzheimer's Society. Food for Thought. London: Alzheimer's Society; 2000.

47. Lee-Winn A, Mendelson T, Mojtabai R. Racial/ethnic disparities in binge eating: disorder prevalence, symptom presentation, and helpseeking among Asian Americans and non-Latino Whites. Am J Public Health. 2014;104(7):1263-1265.

48. Hwang HC, Hwang TJ. Treatment of behavioral and psychological symptoms in Alzheimer's disease. J Formos Med Assoc. 2012; 16:382-389.

49. Luzzi S, Snowden JS, Neary D, Coccia M, Provinciali L, Lambon Ralph MA. Distinct patterns of olfactory impairment in Alzheimer's disease, semantic dementia, frontotemporal dementia, and corticobasal degeneration. Neuropsychologia. 2007;45:1823-1831.

50. Piguet O, Petersén A, Lam BYK, et al. Eating and hypothalamus changes in behavioral-variant frontotemporal dementia. Ann Neurol. $2011 ; 69: 312-319$. 


\section{Supplementary materials}

Table SI Example of memory training protocols between SR group and SR + M group (learn item: "Eating food bite by bite”)

\begin{tabular}{|c|c|c|}
\hline & SR group & SR $+\mathbf{M}$ group \\
\hline Phase I: warm-up ( 2 minutes) & \multicolumn{2}{|c|}{ Introducing each other, orientation to place, time, and people } \\
\hline $\begin{array}{l}\text { Phase IIa: memory training } \\
\text { (40 minutes) }\end{array}$ & $\begin{array}{l}\text { Spaced retrieval memory training: During all } \\
\text { recall interval ( } A, B, C, D, E) \text {, the trainers } \\
\text { arranged reading a newspaper activity for the } \\
\text { subjects }\end{array}$ & $\begin{array}{l}\text { Spaced retrieval memory training combined with Montessori } \\
\text { activities: interval } A \text { and } B \text { arranged weight discrimination } \\
\text { sensory stimulation, interval } C \text { and } D \text { arranged golf ball } \\
\text { scooping activity, and interval } E \text { arranged scooping extension } \\
\text { exercise activity - upward/downward extension }\end{array}$ \\
\hline $\begin{array}{l}\text { Phase III: conclusion } \\
\text { ( } 3 \text { minutes) }\end{array}$ & \multicolumn{2}{|c|}{$\begin{array}{l}\text { Review of day's activity, after which materials used in the activity were put away. Announce the activity to be } \\
\text { done in the next session }\end{array}$} \\
\hline
\end{tabular}

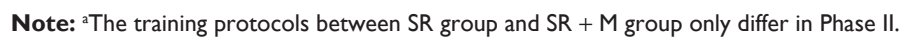

Abbreviations: SR, spaced retrieval training group; SR + M, spaced retrieval and Montessori-based activities training group.

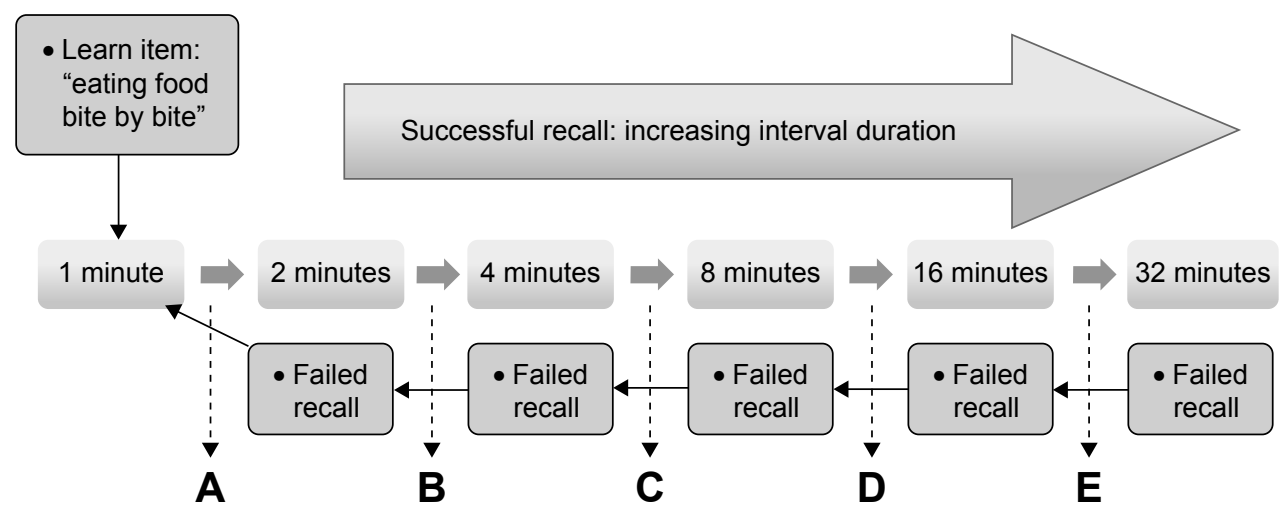

Figure SI Memory training: Phase II process flow.

\section{Publish your work in this journal}

Clinical Interventions in Aging is an international, peer-reviewed journal focusing on evidence-based reports on the value or lack thereof of treatments intended to prevent or delay the onset of maladaptive correlates of aging in human beings. This journal is indexed on PubMed Central, MedLine,
CAS, Scopus and the Elsevier Bibliographic databases. The manuscript management system is completely online and includes a very quick and fair peer-review system, which is all easy to use. Visit http://www.dovepress. $\mathrm{com} /$ testimonials.php to read real quotes from published authors. 